\title{
Overview of ESSL's severe convective storms research using the European Severe Weather Database ESWD
}

\author{
Nikolai Dotzek ${ }^{\mathrm{a}, \mathrm{b}, *}$, Pieter Groenemeijer ${ }^{\mathrm{c}, \mathrm{a}}$, Bernold Feuerstein ${ }^{\mathrm{d}, \mathrm{a}}$, Alois M. Holzer ${ }^{\mathrm{e}, \mathrm{a}}$ \\ ${ }^{a}$ European Severe Storms Laboratory (ESSL), Münchner Str. 20, 82234 Wessling, Germany \\ b Deutsches Zentrum für Luft- und Raumfahrt (DLR), Institut für Physik der Atmosphäre, Oberpfaffenhofen, 82234 Wessling, Germany \\ ${ }^{c}$ Institut für Meteorologie und Klimaforschung, Forschungszentrum/Universität Karlsruhe, Postfach 3640, 76021 Karlsruhe, Germany \\ ${ }^{d}$ Max-Planck-Institut für Kernphysik, Saupfercheckweg 1, 69117 Heidelberg, Germany \\ e HD1 Weather Forecasting Department, ORF Austrian Broadcasting Corporation, Argentinierstr. 30a, 1040 Wien, Austria
}

\section{A R T I C L E I N F O}

\section{Article history:}

Received 2 December 2007

Received in revised form 12 October 2008

Accepted 16 October 2008

\section{Keywords:}

ESSL

ESWD

Database

Reporting

Quality-control

Climatology

Intensity distribution

E-scale

Verification

\begin{abstract}
A B S T R A C T
Severe thunderstorms constitute a major weather hazard in Europe, with an estimated total damage of 5-8 billion euros each year nowadays. Even though there is an upward trend in damage due to increases in vulnerability and possibly also due to climate change impacts, a pan-European database of severe thunderstorm reports in a homogeneous data format did not exist until a few years ago. The development of this European Severe Weather Database (ESWD) provided the final impetus for the establishment of the European Severe Storms Laboratory (ESSL) as a non-profit research organisation in 2006, after having started as an informal network in 2002. Our paper provides an overview of the first research results that have been achieved by ESSL. We start by outlining the reporting practice and quality-control procedure for the database, which has been enhanced by a major software upgrade in the fall of 2008. It becomes apparent that the state of reporting converges to a realistic description of the severe storms climatology, corroborating, for instance, earlier estimates of tornado occurrence in Europe. Nevertheless, a further rise in the number of reported events must be expected, even without the presence of any physical trends. The European tornado and damaging wind intensity distributions as a function of the Fujita scale are quantitatively similar to long-term distributions from the USA, except for a strong underreporting of weak events (F0) that still persists in Europe. In addition, the ESSL has recently proposed a new wind speed scale, the Energy- or "E-scale" which is linked to physical quantities and can be calibrated. Finally, we demonstrate the large potential of ESWD data use for forecast or nowcasting/warning verification purposes.
\end{abstract}

(C) 2008 Elsevier B.V. All rights reserved.

\section{Introduction}

Severe thunderstorms, with their attendant strong winds, hail, flooding, and tornadoes, are common phenomena in many European countries, leading to a total damage estimate of 5 to 8 billion euros per year (source: Munich Re Group). Extreme events like an F4 tornado in France and an F3 downburst

\footnotetext{
* Corresponding author. European Severe Storms Laboratory (ESSL), c/o DLR-IPA, Münchner Str. 20, 82234 Wessling, Germany. Tel.: +49 815328 1845; fax: +49815328 1841 .

E-mail address: nikolai.dotzek@essl.org (N. Dotzek).

URL: http://essl.org/people/dotzek/ (N. Dotzek).
}

in Austria in 2008 exemplify these damage totals. However, documentation and analysis of European severe convective storms in the scientific literature have been relatively sparse from about 1950-2000. Most notably, a pan-European database of in situ severe storm reports was unavailable even a few years ago.

It is well established that severe thunderstorms require the presence of specific "ingredients" (e.g., Doswell et al., 1996) such as the presence of moisture and instability, a source of upward motion and strong vertical wind shear. An important question is which processes lead to the simultaneous occurrence of those ingredients at a certain point. In answering this question for European storms, a particular challenge is posed 
by the many mountain ranges and the complex coast line of Europe. These likely play important roles in creating regionally favourable circumstances for severe thunderstorms, for example by the mesoscale flows that they induce. A better knowledge of European severe thunderstorms could bring new insights into these issues and also foster climatological evaluation and forecasting of severe thunderstorms worldwide.

Accordingly, the European Severe Storms Laboratory (ESSL) was founded in 2002 as an informal network of European scientists and formally established in 2006 as a non-profit research organisation. Legally, the ESSL is a registered association (eingetragener Verein, e. V., under German law) with the following primary statutory purposes:

- basic and applied research on severe weather events;

- development and quality-control of the European severe weather database, ESWD;

- support or organisation of the European Conferences on Severe Storms, ECSS.

One important thing to note is that neither issuing forecasts nor warnings are among the activities of the ESSL, as these are core duties of the European national meteorological and hydrological services (NMHS). However, this paper will demonstrate that the ESWD data provide many new opportunities to verify forecast or nowcasting products or warnings.

ESSL's development status, as well as its research planning for the next years, includes the involvement in EU-funded research projects and initiatives. Concerning international collaboration, the ESSL had signed a cooperation agreement with the European Meteorological Society (EMS) in September 2007. Furthermore, already four NMHS are partners of the ESSL: AEMet (Spain), DWD (Germany), NIMH (Bulgaria) and ZAMG (Austria). Of these, DWD is also an institutional ESSL member since 2007. EUMETSAT became a member as well in the fall of 2008. Cooperation with additional NMHS, EUMETNET (e.g. with respect to www.meteoalarm.eu), or the ECMWF is desired on the road to establishing the ESSL within the European atmospheric science community.

As the ESSL still is a young start-up organisation, its scope of research must presently focus on topics which do not require large resources. Most of the science during the last years was related to applications of the ESWD database, and this paper touches upon the most prominent points in the following sections. So, here we only briefly review the third pillar of ESSL activity, the ECSS conferences.

An initial conference on "European Tornadoes and Severe Storms" was held in Toulouse in 2000, kindly supported by Météo-France. The conference participants agreed that this meeting was an important first step in fostering further research coordination and collaboration in this scientifically and economically highly relevant research area. From the follow-up conference in Prague in 2002 on, the name of the conference series was changed to "European Conference on Severe Storms". At the third ECSS in León in 2004, it was decided to have a three-year break before the next ECSS, to avoid having the ECSS and the AMS Severe Local Storms conference in the USA in the same year. Indeed, participation by researchers from the USA and scientific exchange with severe convective storms researchers in Europe were significantly enhanced at the ECSS in Trieste in 2007, and it is expected that this development will continue during the next ECSS in 2009.

ESSL founding members have been involved in the organisation of two of the previous conferences (2002 and 2007), and the ESSL as an organisation became involved in the preparation of the 2007 conference, where also ESSL's Heino Tooming award was presented for the first time, honouring an outstanding presentation by a team led by a European scientist and involving colleagues from at least one more European country. The next ECSS in Landshut, Germany from 12-16 October 2009 will be organised by ESSL and also present the second Tooming award.

Further information on the ESSL and its development is available from its websites www.essl.org as well as www.eswd. eu and www.ecss.eu. In addition to its main site, the ESWD development is documented at essl.org/projects/ESWD/. The present paper is organised as follows: Section 2 outlines the severe storm reporting practice, ESWD quality-control, and data exchange with collaborating organisations. Section 3 presents the applications of the ESWD database and ESSL's other initial research activities. Sections 4 and 5 provide discussion and conclusions, respectively.

\section{ESWD database management}

The main goal of the ESWD database (Groenemeijer et al., $2004,2005)$ is to collect and provide detailed and qualitycontrolled information on severe convective storm events in Europe using a homogeneous data format and web-based, multi-lingual user-interfaces where both the collaborating NMHS and the public can contribute and retrieve observations.

The following categories of severe weather are included in the ESWD at this time: Straight-line wind gusts $\left(v>25 \mathrm{~m} \mathrm{~s}^{-1}\right)$, tornadoes, large hail (diameter $>2 \mathrm{~cm}$ ), heavy precipitation, funnel clouds, gustnadoes, and lesser whirlwinds. To extend the range of covered phenomena is among ESSL's objectives, and envisaged by the flexible design of the data format (see www.essl.org/reports/tec/ESSL-tech-rep-2006-01.pdf).

\subsection{Severe weather reporting in Europe}

After two years of test operations, 2006 was the first year with operational ESWD service. Dotzek (2003) has provided an updated estimate of tornado occurrence in Europe based on a survey among the ECSS 2002 participants representing 25 countries, and compared it to the older estimate by Wegener (1917). Thus, we can now make a first evaluation how the numbers from the 2003 estimate correspond to the actual ESWD reports.

Fig. 1a provides a map of the 3424 ESWD reports in 2007. Table 1 further shows the temporal evolution of reports of the most prominent phenomena in the ESWD, allowing for a comparison with earlier estimates. Dotzek (2003) reported a yearly total of $169+/-9$ observed tornadoes over land, as well as $160+/-3$ waterspout reports across Europe. At the time, the underreporting was estimated to be about $50 \%$. Consequently, the available observations led to $329+/-12$ tornadoes and waterspouts per year, while the estimated total was $697+/-36$.

Table 1 reveals that indeed, 2006 saw roughly 700 reports of tornadoes and waterspouts in Europe, whereas the other years from 2004 on had numbers ranging from 350 to 500 

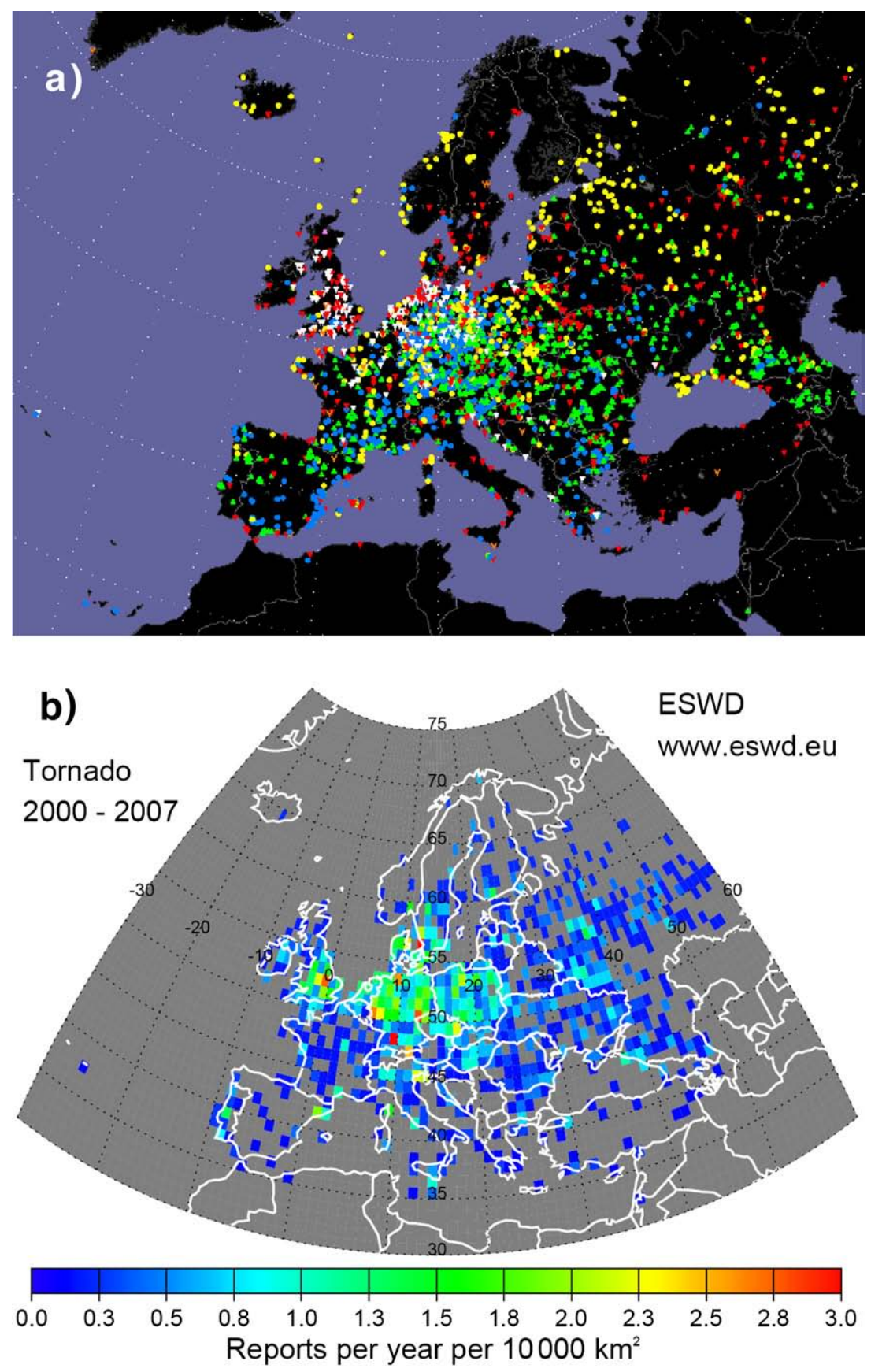

Fig. 1. All ESWD reports for the year 2007 (a, $n=3424)$. Red: tornadoes, yellow: damaging wind, green: large hail, blue: heavy precipitation. Date of ESWD inquiry: 7 October 2008. Panel (b) shows a first short-term (2000-2007) tornado incidence map based on the yearly analysis on 16 April 2008 . Incidence as the primary metric of hazard is given in reports per year per $10,000 \mathrm{~km}^{2}$.

reports per year. The close correspondence between the estimated numbers by Dotzek (2003) and the actual reports in 2006 is certainly coincidental, but it also reveals that the 2003 estimates were not exaggerated. In fact, there are signals indicating that a further increase in reports must be expected, without signifying a real trend in occurrence. These include (a) the rather low number of reported waterspouts compared to the number of tornadoes over land, and (b) the not yet completely homogeneous reporting density over Europe (cf. Fig. 1a), sometimes reflecting discontinuities across national borders.

Similar or even stronger underreporting must be expected for the funnel cloud reports in Table 1, even though the jump from 4 to 10 reports until 2002 to more than 250 reports per year now is already impressive. A parallel evolution of reports can be seen for the straight-line winds, hail, and heavy precipitation reports. Their numbers have strongly risen since 2005. The fact that, for instance, the damaging wind or hail 
Table 1

Evolution of the number of primary reports in the ESWD (tornadoes over land and water, funnel clouds, damaging winds, large hail and heavy precipitation) from 2000 to 2008 .

\begin{tabular}{llllrrr}
\hline Year & $n$ & $n$ & $n$ & $n$ & $n$ & $n$ \\
& Tornado & Waterspout & $\begin{array}{l}\text { Funnel } \\
\text { cloud }\end{array}$ & Wind & Hail & $\begin{array}{l}\text { Heavy } \\
\text { precip. }\end{array}$ \\
\hline 2000 & 84 & 21 & 10 & 14 & 68 & 10 \\
2001 & 93 & 11 & 4 & 53 & 128 & 32 \\
2002 & 167 & 37 & 9 & 94 & 172 & 71 \\
2003 & 189 & 57 & 39 & 172 & 233 & 80 \\
2004 & 275 & 79 & 82 & 201 & 344 & 105 \\
2005 & 350 & 123 & 93 & 409 & 460 & 226 \\
2006 & 512 & 172 & 66 & 1039 & 685 & 672 \\
2007 & 319 & 114 & 246 & 640 & 1115 & 927 \\
$2008^{*}$ & $210^{*}$ & $78^{*}$ & $269^{*}$ & $820^{*}$ & $912^{*}$ & $1127^{*}$ \\
\hline
\end{tabular}

Note that tornado and wind report raw data may contain additional information on accompanying hail or precipitation (secondary events). The ESWD online test phase began in 2004, the operational phase started in 2006 , and the data for 2008 are preliminary $(*)$. Date of ESWD inquiry: 7 October 2008 .

reports now exceed the number of tornadoes is physically plausible: These phenomena are much more likely to occur than tornadoes, as fewer conditions must be satisfied for their genesis. Thus, we are confident that the basic climatological reporting characteristics in the ESWD are in the process of converging toward their "true" distributions.

One way to mitigate any underreporting is to extend ESSL's collaboration with NMHS in Europe to augment and homogenise the database. Another way, which is in fact one of the major strengths of the ESWD, is to exploit web 2.0 functionality and to involve the public in the data reporting. The public ESWD web interface at www.eswd.eu allows submitting reports from all over Europe and the entire Mediterranean region. Due to the real-time capability of the software, the new reports appear on the map immediately following submission. The public input strongly helps to close gaps in the data coverage and to increase the data basis for climatological evaluation. Presently, the majority of reports come from the ESWD maintenance team or via the public web interface, but the percentage of reports by partner NMHS is increasing. Routine observations like SYNOP reports are not yet regularly introduced into the ESWD, but feasibility studies to do so have been made (e.g., for waterspouts, Dotzek et al., 2008) to assess the potential benefits of these automated reports. At this time, most of the NMHS reports are entered to the ESWD by operational NMHS staff.

Our experience with the quality of public reports is good. The detailed ESWD reporting template forms apparently discourage fake reports, and occasional errors in true reports are confusion of local time and UTC, for instance, and can be corrected during quality-control. Public reports often come repeatedly from the same people, interested in weather phenomena and with at least some expertise. In general, more care must be taken when using media information, as these can be exaggerated (e.g., calling events "tornadoes" which had in reality been damaging wind gusts) or use rather stereotype wording which provides little meteorological detail. Here, the practice to perform cross-checking via independent sources helps to judge the reliability of individual public ESWD entries. In order to keep the data sources in the ESWD traceable, however, the public reports are marked and can also be evaluated separately.

Concerning the time period before 2004, some countries like Germany have already converted their local severe storm reports to ESWD format. Here, the database can be extended backward in time at least to 1950, and in the case of Germany to the late 19th century. Yet for many other European countries for which severe storm data archives do exist as well, the effort to convert these data to ESWD format remains to be undertaken. This has been the subject of a number of project proposals with the aim to attain homogeneous data coverage in Europe at least from 1950 on, and is an ongoing challenge.

ESSL's efforts are backed up, fortunately, by the parallel and independent development of storm spotter networks in Europe, like Skywarn in several countries (www.skywarn. eu) or KERAUNOS (www.keraunos.org) in France. These accumulate severe weather expertise, recruit, train, and approve new spotters (like Skywarn), and often also gather historical severe weather reports from their countries. In addition, ESSL and Skywarn currently develop an English version of a detailed Fujita-scale (F-scale, Fujita, 1971) and TORRO-scale (T-scale, Meaden, 1976) damage description for man-made structures and vegetation, valid for central Europe. It is based on the original version in German as elaborated by Dotzek et al. (2000) in cooperation with Munich Re, and extended by Hubrig (2004). This updated description contains explanatory illustrations and will be made available at www. essl.org/research/scales/.

\subsection{ESWD quality-control and data exchange}

Fig. 1a and Table 1 showed the large number of reports in the ESWD in the three years 2006-2008, most of which have originated either from ESWD maintenance or the public. These large numbers pose a challenge for an appropriate quality-control (QC) procedure, which is currently one of the most important tasks of the ESSL in operating the ESWD. Aside from cross-checking individual reports, the QC also includes merging of multiple reports of one event according to the criteria set up in the ESWD data format, or a later change of event type, for example if based on new evidence, an initial "tornado" report must be changed to "damaging wind gusts" or vice versa.

The basic procedure foresees that the ESSL is responsible for QC of all reports coming in via the public interface while the cooperating NMHS are responsible for QC of the severe weather reports in their country, as entered, for instance, through their locally installed ESWD software. This is illustrated in Fig. 2a for the ESWD software version 2 and an exemplary setup with the NMHS partners DWD and ZAMG (recall that the Spanish and Bulgarian weather services AEMet and NIMH are cooperation partners as well).

Each NMHS partner performs a three-level quality-control on the data gathered at its ESWD installation, while the ESSL is responsible for the three-level QC of the public reports and those entered by its ESWD maintenance team. Data exchange between the ESSL and the cooperating NMHS takes place in regular intervals, currently usually at least once a day. Herein, the NMHS partners upload their new or revised data to the ESSL main server, and download the new or updated public 


\section{a) ESWD version 2}

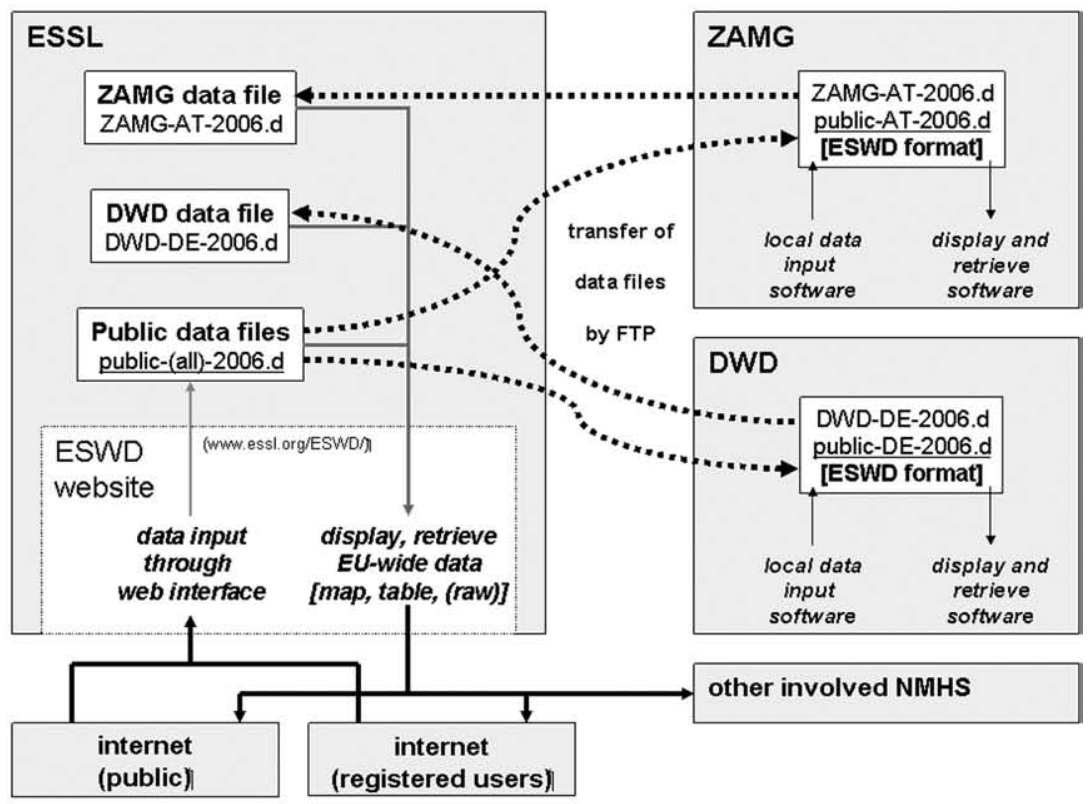

\section{b) ESWD version 3}

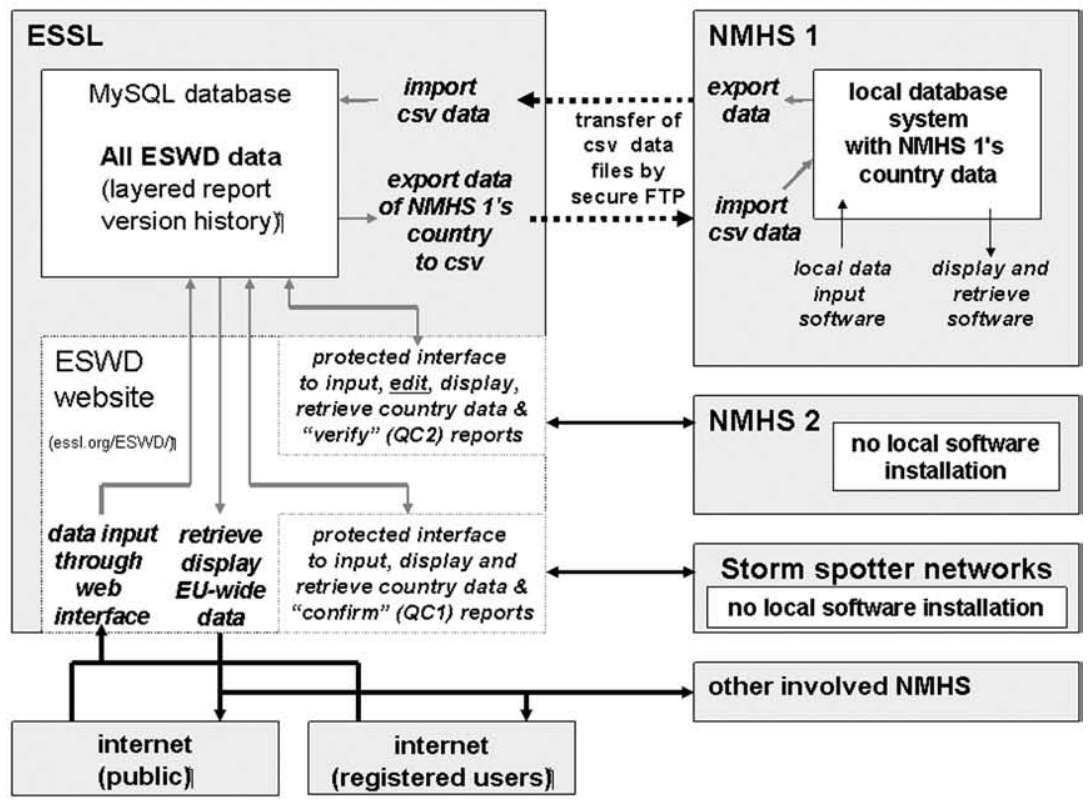

Fig. 2. Schematic of the ESWD data stream between the central ESSL server, local installations at collaborating NMHS, as well as registered users and the public. (a) ESWD version 2 setup with exemplary partners DWD and ZAMG. Note the exchange of files, not parts of a relational database. (b) Situation with the new ESWD version 3, based on a MySQL database on the ESSL server. Here, NMHS have more options to collaborate with the ESWD, e.g., NMHS 1 via true database exchange, NMHS 2 via a customised user portal at ESSL, or in the simplest case via the public ESWD portal.

reports of severe weather in their respective countries. The three-level QC process specifies that any initial report to the database receives the lowest QC-level QCO (or QC1 in reports entered by partner NMHS or ESSL if the initial information is already confirmed by several sources). Further verification of the report, including editing and augmenting the information contained therein, can lead to an upgrade to levels QC1 or QC2. 
The meaning of the three QC-levels in the ESWD and the underlying regulations for their assignment are as follows:

- QC0: "as received" (new report, only retained if at least plausibility can be ascertained);

- QCO+: "plausibility checked" (assigned by partner organisation or ESSL);

- QC1: “report confirmed” by reliable sources (assigned by partner organisation or ESSL);

- QC2: "event fully verified" i.e. all information about this event is verified, consistent and comes from reliable sources (assigned by partner NMHS or ESSL).

On the ESWD version 2 public web portal, the verbalisation of these QC-levels had not yet been as detailed as above. However, in the fall of 2008, a completely revised ESWD software version has become operational. Aside from the features described below, this ESWD version 3 displays the above terminology for the QC-levels, and highlights the fresh QCO reports in the tabular list compared to the already checked $\mathrm{QCO}+$ entries. This visual distinction between QCO and QCO+ reports in the list will facilitate the quality-control process during the main severe weather season when many new reports come in, and when it has to be clear at first glance which reports still require at least the initial plausibility check. Ideally, a few days after an extreme weather episode, all QCO reports should have been either raised at least to QCO+ or deleted.

Fig. 2b schematically outlines the characteristics of data exchange with the new ESWD version 3. There are now a number of options how NMHS can design the communication with the database. The first option, chosen by DWD for instance, is to maintain a local ESWD software installation which manages the country-level data exchange with the main server at ESSL and which also handles the internal data flow towards the NMHS' in-house climate database system. The option selected by exemplary NMHS 2 in Fig. $2 \mathrm{~b}$ is to have a tailored user interface at the ESSL server which allows editing of country-level data, assigning QC-levels up to the final QC2, and retrieving raw data in ESWD- or csv-format. The most basic contribution of any NMHS to the ESWD would be to use the public ESWD web portal and to get dedicated NMHS staff acquainted with the procedure of reporting to the ESWD. This latter option may be most convenient during a test phase of cooperation.

The new ESWD version 3 will also allow providing, for instance, the Tornado and Storm Research Organisation (TORRO), or storm spotter networks like Skywarn, with a dedicated user interface to submit or retrieve data and confirm public reports from their countries by raising the QC-level up to QC1. As quite a level of severe weather expertise is present with these organisations, such a user interface would help to make their reports more prominent and visible compared to the option of using the public ESWD interface which is also open to people with an unknown level of expertise. In addition, the effort to quality-control the genuinely public reports would thus be shared among a larger group, involving trained people from the country from where the event was reported. This option is especially promising in countries for which collaboration with their NMHS has not yet been established.

In order to assist the quality-control of the ESWD data, its data format also contains fields with metadata information. For instance, aside from the pure tornado or straight-line wind intensity rating, there are also fields describing on what kind of information this intensity rating was based. Other metadata fields name the sources providing the report or uncertainty ranges for the time of event occurrence, for instance. Particularly important in verification applications of the ESWD is the information when the report was added to the database. From this, one can infer if the report would in principle have been available in quasi-real-time for warning decisions on the day of the event, or if it was entered only a few days afterwards, based on then-available information from the media or other sources, like post-event damage surveys. ${ }^{1}$

Therefore, the ESWD data format allows for both detailed event information and thorough quality-control, including tracking of how the data in a particular report evolved over time in the QC procedure: In ESWD version 3, the complete revision history is stored as individual layers in the database entry. Starting in 2007, the first part-time ESSL staff have begun to enter and quality-control reports, not only from the current year, but also back in time. There are close contacts with colleagues at the cooperating NMHS concerning the QC of events reported from their countries and in merging double reports of events which were entered to the database both by the NMHS and via the public interface. These first years of ESWD operations are a learning period for developing best practices in handling the QC challenge. But the ESWD applications reviewed in the next section clearly show that taking this challenge is a worthwhile task.

\section{Applications of the ESWD database}

ESWD development was motivated by its wealth of potential applications in handling the challenges of operational meteorology. Severe convective weather events strongly depend on micro- and mesoscale atmospheric conditions, and in spite of the threat that they pose to life and property, they usually escape the meshes of existing operational monitoring networks. Besides, such events are often embedded in systems acting on a larger scale, and even if damage is local, severe weather can continue for hours or days and affect more than one European country during its lifespan. When dealing with severe weather events, researchers and forecasters need to know when and where these events have taken place to enhance conceptual models or theories, to assess the quality of their forecasts and warnings and to evaluate the employed forecast and warning decision procedures.

An important component to the enhancement of the forecasting process is to increase the capabilities of numerical model guidance to forecasters. To this aim, numerical models use ever finer grids and have become capable of operationally resolving deep convection explicitly. Severe weather phenomena like hail streaks, downbursts and tornadoes will, however, remain too small to be explicitly resolved for some time to come. And even when models can actually be run at ultra-high resolution, the level of uncertainty in their required microscale initial conditions will still make it unlikely that model predictions could be used "as is". Therefore, to

\footnotetext{
1 ESSL performed a ground and aerial damage survey of the F3 downburst in Austria on 1 March 2008. Other recent examples are described in the papers by Dotzek et al. (2007) or Dotzek and Friedrich (2008).
} 
translate model output to an actual forecast decision if such phenomena will occur, and if so, where and when, remains a non-trivial problem. Irrespective of the potential solutions to this, it must be clear that these cannot be found without knowledge of where severe weather did develop in reality.

Most NMHS also want to be able to gather climatological information on severe weather, while insurance and reinsurance companies require a hazard (and subsequently risk) assessment of severe local storms. The ESWD is becoming a source of the data required to carry out a systematic evaluation of severe weather events and the damage that they caused: A prerequisite to obtaining a robust and homogeneous climatology and hazard analysis of severe local storms in Europe. Taking all this into account, applications of the ESWD include, but are not limited to:

- report-based climatology and hazard assessments;

- provision of background data for research, e. g., storm initiation and life cycles over complex terrain;

- forecast, nowcasting or warning verification;

- training activities for researchers or NMHS staff.

\subsection{Hazard assessment}

Fig. 1b shows the first pan-European tornado incidence map ever produced from actual reports, albeit still based on a sub-climatological eight-year time period: 2000-2007. Tornado incidence given as number of reports per year per $10000 \mathrm{~km}^{2}$ is the primary metric of the hazard (cf. Court, 1970). As the database has not yet reached satisfactory completeness in Europe before, say 2004, this preliminary incidence map presently suffers from underreporting in south-western and eastern Europe. However, a region of enhanced tornado incidence extending from the United Kingdom over the Benelux region, northern Germany and Poland towards the Baltic States emerges from the data. This region is consistent with the European "tornado alley" already described by Wegener (1917). Hence we are confident that this signal will persist in future evaluations of the ESWD data. As about 3500 reports are entered to the ESWD each year, the data-sparse regions should also fill rather quickly.

In the 2000-2007 time period, the incidence maps of the other prominent ESWD phenomena are still biased towards the data from Germany. The historical data from that country have already been completely included in the ESWD, while the data from many other surrounding countries are rather sparse before 2004. However, when interpreted with caution, the following traces of likely climatological signals can be found: Waterspouts are reported all along the European coasts (less so over open water due to lack of observers), but appear to find particularly favourable environments near the Balearic islands, the Italian west coast and the entire Adriatic Sea shoreline. The North and Baltic Sea, as well as the larger lakes in Switzerland are also known for their reliable waterspout seasons (cf. Dotzek et al., 2008).

Funnel cloud reports are presently mainly available from the United Kingdom, the Netherlands, and Germany. Damaging winds appear to occur relatively homogeneously in central Europe, while a general high frequency of winds above $25 \mathrm{~m} \mathrm{~s}^{-1}$ emerges in Iceland. Similarly, the distribution of heavy precipitation incidence does not yet reveal pronounced hot spots, but does show at least a tendency for more frequent reports from southern France, the Spanish Mediterranean coast and the Balearic Islands. Somewhat more detail is visible in the large hail incidence map, where aside from southern Germany, also south-western France, the eastern Alpine region (Southern Austria, Slovenia), as well as Romania and the Caucasus region have many hail reports per unit area each year.

The incidence maps are updated and published annually on www.essl.org/research/. During the last years, about 3500 new reports per year were added to the ESWD. If this continues, the climatological significance of the maps will increase rapidly over the next few years. Nonetheless, there is still a long way to go before the ESWD will have reached a level of completeness similar to the severe storms database in the USA.

\subsection{Intensity distributions and the E-scale}

Climatological results from a subset of the pan-European ESWD data have been presented by Dotzek (2001) and more recently by Bissolli et al. (2007). Another evaluation is shown in Fig. 3a and Table 2, in which the tornado intensity distribution over F-scale of all rated tornadoes in the ESWD
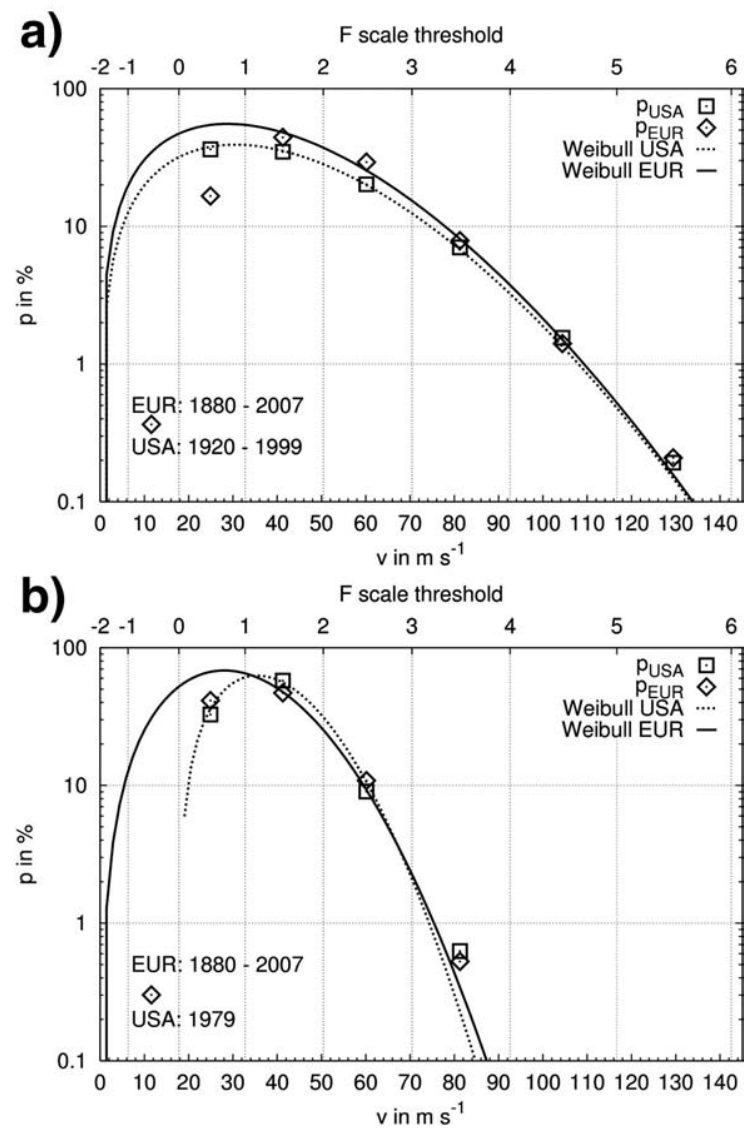

Fig. 3. Tornado and damaging wind intensity distributions over $F$-scale, cf. Table 2: (a) Tornadoes in Europe from 1880-2007 (1919 rated of all 3500 reports, diamonds) with Weibull fit (solid), and in the USA from 1920-1999 (45761 reports, boxes) with Weibull fit (dotted). (b) Straight-line winds in Europe from 1880-2007 (1327 rated of all 3075 reports, diamonds) with Weibull fit (solid), and in the USA in 1979 (798 reports, boxes) with Weibull fit starting at $\mathrm{FO}$ intensity. 
from $1880-2007$ ( 1919 of $3500=54.8 \%$ ) is compared to that of the USA in the time span 1920-1999. The long period of the US reports includes decades in which mainly strong (F2, F3) or violent (F4, F5) tornadoes have been reported, up to the 1990s in which detection efficiency had become so high that the vast majority of reported tornadoes were weak (F0, F1, cf. Dotzek et al., 2005). This mixture of reporting efficiencies in the USA between 1920 and 1999 resembles the currently still nonstationary and inhomogeneous tornado reporting in Europe. Therefore, any degree of similarity between the EU and US distributions should emerge best from these long time series.

Fig. 3a and Table 2 illustrate that the present intensity distribution of tornadoes in Europe is indeed very similar to that in the USA, except for the European F0 tornadoes for which a strong underreporting appears to persist. First, the consistency of both intensity distributions is in line with the global analyses by Dotzek et al. $(2003,2005)$ and Feuerstein et al. (2005) who modelled the tornado intensities by Weibull distributions. Second, judging from the US-experience over the last five decades (Verbout et al., 2006), we can expect the number of reported F0 tornadoes to strongly rise in the future, with public awareness levels and reporting standards becoming more homogeneous all over Europe.

Improving completeness of the database will also enable statistical modelling of tornado swath widths and lengths by Weibull distributions as well as their relation to intensity, as demonstrated for the USA by Brooks (2004). Knowledge of the area affected annually by tornadoes of a given intensity in Europe is crucial for computing the tornado probabilities at a point (Thom, 1963). The path length and width information is part of the ESWD data format, but many reports still do not provide both length and width data.

For comparison, Fig. 3b and Table 2 also show the damaging wind intensity distribution over $F$-scale for all rated wind events in the ESWD from 1880-2007 (1327 of $3075=54.8 \%$ ) in comparison to exemplary numbers from the USA in the year 1979 (Fujita, 1981). Note that in the USA, damaging wind reports are only available since 1955 , so no similarly long time series like for tornadoes can be given. Consistent with US straight-line wind reports in general, the European intensity distribution is also limited to a maximum of F3 intensity, with the latter making up only a very small fraction of the events. Again, a strong underreporting of weak

\section{Table 2}

Intensity distributions of tornadoes and damaging winds (number of reported events, $N$ ) over F-scale for Europe (1880-2007) based on an ESWD inquiry on 7 October 2008 and for tornadoes in the USA (1920-1999) based on Dotzek et al. (2003).

\begin{tabular}{|c|c|c|c|c|c|c|}
\hline \multirow[t]{2}{*}{$F$} & \multicolumn{3}{|c|}{ Tornadoes over land } & \multicolumn{3}{|c|}{ Damaging winds } \\
\hline & $N_{\text {Europe }}$ & $N_{\text {USA }}$ & $N_{\text {USA }}^{*}$ & $N_{\text {Europe }}$ & $N_{\text {USA }}$ & $N_{\text {USA }}^{*}$ \\
\hline-1 & 7 & 0 & 0.0 & 4 & 0 & 0.0 \\
\hline 0 & 319 & 16589 & 695.7 & 549 & 261 & 434.0 \\
\hline 1 & 849 & 15921 & 667.7 & 623 & 460 & 764.9 \\
\hline 2 & 562 & 9239 & 387.4 & 144 & 72 & 119.7 \\
\hline 3 & 151 & 3214 & 134.8 & 7 & 5 & 8.3 \\
\hline 4 & 27 & 710 & 29.8 & 0 & 0 & 0.0 \\
\hline 5 & 4 & 88 & 3.7 & 0 & 0 & 0.0 \\
\hline Total & 1919 & 45761 & 1919.1 & 1327 & 798 & 1326.9 \\
\hline
\end{tabular}

For US damaging wind reports, the one-year data of Fujita (1981) is shown. For comparison, the USA data have also been scaled to the same totals as for Europe: $N^{*}$ USA, cf. Fig. 3. events appears to persist. The Weibull modelling according to Dotzek et al. (2005) allows us to estimate this current level of underreporting. We find an underreporting in Europe of about $44 \%$ for the tornadoes, and of $35 \%$ for the damaging winds, mainly caused by the apparent lack of F0 reports.

Assignment of tornado or straight-line wind intensities has been a subject of long debate and controversy. The Fujita scale (Fujita, 1971) has gained the widest acceptance internationally over the recent two decades compared to the TORRO scale (Meaden, 1976). Yet it has also often been criticized for being inadequate under certain circumstances, for instance when variations in building strength along the damage path play a role. These criticisms are expressed by Doswell et al. (2008) in greater detail, in particular with respect to the "Enhanced Fujita" or EF-scale, a damage scale developed in the USA and implemented there in 2007. But as shown by Doswell et al. (2008), the EF-scale itself is by far not free from criticisms, despite some conceptual improvements over the original F-scale.

The ESSL has recently proposed the Energy- or "E-scale" (Dotzek, 2008) as a wind speed scale that can be calibrated and that is coupled to physical quantities $X$ like mass flux or momentum density $(M=\rho v)$, kinetic energy density $(E=\rho /$ $\left.2 v^{2}\right)$ or the kinetic energy flux density $\left(P=\rho / 2 v^{3}\right)$. In short, the nonlinear scaling relation in these quantities

$X_{*}\left(X-X_{0}\right)^{n}=a_{x} v^{n}$

results in a universal scale relation which is always linear in velocity $v$ :

$v(X)=v_{*}\left(X-X_{0}\right), \quad$ with $\quad v_{*}=\left[a_{x}^{-1} X_{*}\right]^{1 / n}$.

In Eq. (1), the scaling quantity $X_{*}$, the air densitydependent prefactor $a_{x}$ and the exponent $n$ depend on the physical observables $M, E, P$ in which the non-linear scaling is performed. The scaling velocity $v_{*}$ in Eq. (2) is determined by the choice of the critical values $M_{*}, E_{*}$, or $P_{*}$, thus allowing for calibration of the scale.

Note that the well-known Mach scale is a special case of the E-scale. In the initial presentation by Dotzek (2008), the scaling velocity was chosen to facilitate conversion of existing worldwide $F$-scale data to their corresponding $E$-scale intervals. Aside from its ability to be calibrated, the E-scale counterpart of the $F$-scale (named $E_{F}$-scale) maps the F-scale classes $[F-2, \ldots, F 5]$ to the $E$-scale classes $\left[E_{F}-1, \ldots, E_{F} 6\right]$. This has the advantage that the present relevant $F$-scale velocity range is covered by one more class when using the $E_{F}$-scale, thus also offering an improved basis for statistical climatology based on intensity distributions. A thorough comparison of the E-scale concept to the EF-scale mentioned above has been given by Dotzek (2008). It remains to be seen if the $E$-scale will become accepted in general, and if it might serve as a sound worldwide specification of wind speed thresholds for the detailed damage descriptions as proposed by the EF-scale.

\subsection{Verification}

To demonstrate the potential application of ESWD reports for verification purposes, we first deal with a comparison of ESWD reports to severe thunderstorm threat-level Convective Forecasts by the ESTOFEX network (www.estofex.org) and 
DWD warnings in a severe weather episode from 26-31 July 2005 (cf. Dotzek et al., 2006). Fig. 4a shows the ESWD reports of 29 July 2005 (still within the ESWD test phase): The peak of this severe weather episode.

On 27 July, mostly damaging winds and a few tornadoes occurred in Germany to the west and north of Frankfurt. On the 28th, damaging winds and heavy precipitation concentrated over northern Germany, while in the United Kingdom, the F2-Birmingham tornado occurred (Marshall and Robinson, 2006). 29 July brought southwest-northeast-oriented corridors of heavy precipitation from the Benelux to the Baltic Sea, and of damaging winds, hail and some tornadoes from the French and Swiss Jura to western Poland. On this day, also a low-precipitation (LP) supercell producing very large hail in the Chemnitz region in eastern Germany was well-documented by storm chasers.

The ESTOFEX network is a registered ESWD user and routinely applies the reports in their verification procedure. The ESWD reports of 29 July in Fig. 4a reveal that the risk-level forecast by the ESTOFEX network captured the areas with actual severe weather occurrence rather well, with the main corridors of ESWD reports roughly at the right and left flanks of the threat-level 2 area. In a further step, Dotzek et al. (2006) compared DWD severe weather warnings and ESWD reports for 27 and 29 July 2005. For these two days, DWD's severe weather warnings in Germany generally showed that in most cases of severe convective storm events, a severe thunderstorm warning was prepared, issued, and active. In 2005, DWD did not yet operationally provide dedicated tornado warnings. Instead, any tornado threat was subsumed in the warnings of thunderstorms capable of producing damaging winds, hail or heavy precipitation. For the selected severe weather period, however, a DWD warning of thunderstorms in the affected county existed in all tornado cases reported to the ESWD.

Fig. 4b provides an example of a satellite-based nowcasting verification (Dotzek and Forster, 2008) based on the Cb-TRAM algorithm (Zinner et al., 2008). The complete study by Dotzek and Forster (2008) was performed for five days with warm-season severe convection. The day chosen for Fig. 4b was 25 May 2007, when widespread activity of mostly isolated thunderstorms evolved from France to Poland. Based on Meteosat-8 SEVIRI data, Cb-TRAM marks regions with thunderstorms in three stages of their life-cycles: (a) onset of deep convection, (b) rapid vertical cloud development, and (c) mature thunderstorms. In the time frame of Fig. 4b, three ESWD reports can be seen, one large hail and a heavy precipitation report connected to detected "mature thunderstorm" polygons, and another large hail report at a cell with detected "rapid development".

For 25 May 2007, 47\% of all ESWD reports were falling exactly within the Cb-TRAM polygons, and on two other of the five days studied, this ratio also exceeded $40 \%$. Note that the severe weather events need not exclusively occur within Cb-TRAM's detected polygons, but can be shifted laterally or up/downstream from the storms due to their specific thunderstorm morphology. ESWD reports also sometimes appeared at a detected cell, but just before or just after a $\mathrm{Cb}$ TRAM detection period. So, while no exact correspondence between Cb-TRAM polygons and ESWD reports is strictly required from a physical point of view, the correspondence ratios of more than $40 \%$ are encouraging. Interestingly, in the case of winter thunderstorms embedded in extratropical cyclones, even an opposite situation may arise: There may be many ESWD reports (like the 163 reports on 1 March 2008 for cyclone "Emma", cf. Dotzek and Forster, 2008), whereas the satellite-based nowcasting optimised for warm-season convection did not detect the severe potential of the lowtopped cold-season storms at all.

These examples underpin the applicability of ESWD groundtruth severe storm reports for verification purposes. In principle, any forecast fields and nowcasting products related to severe thunderstorm occurrence or to area-based warnings could be evaluated against actual severe convective storm reports. Examples of further such quantities are the Dynamic State Index (DSI, Névir, 2004), or the Extreme Forecast Index (EFI, Lalaurette, 2003) developed by the ECMWF. The DSI is based on energy-vorticity theory and is sensitive to all nonstationary and diabatic processes in the atmosphere. In contrast, the EFI measures how far members of an ensemble prediction system deviate from the model-derived climatology. So, both DSI and EFI are quite different conceptually, but lead to similar kinds of information, namely synoptic fields highlighting regions in which extreme events are likely. For any such kind of spatial fields, the ESWD reports appear to be good candidates for verification purposes.

\section{Discussion}

The results shown here mainly rely on the ESWD database. The range of its applications extends from basic climatology to statistical climatology and hazard assessments as well as to the demonstration of its use in verification studies. Clearly, a pan-European database of in situ thunderstorm reports is a useful development and provides many research opportunities which were unavailable before.

Despite the accomplishments outlined in this paper, there is still a long way to go until the ESWD can be called a truly mature database. As mentioned before, underreporting of specific events is still notable in a number of regions in Europe, in particular prior to 2004. Yet the input to the ESWD by the public and the ESWD maintenance has led to the large increase in reports over the last years, as documented by Table 1. Bissolli et al. (2007) showed for the subset of German severe storm reports from 1950-2003 that this is a longerterm trend and, for tornadoes, mainly stems from a dramatic increase in reported weak events, especially of the F0 category. It is often conjectured that this trend might be the footprint of global climate change on severe local storm occurrence. However, it is extremely unlikely that this is the dominant cause. While an influence of global warming on severe thunderstorms cannot be ruled out in principle, any such trend will definitively be overwhelmed by the mere fact that severe storm reporting itself has become so much more efficient over the last one or two decades (cf. IPCC, 2007).

Besides, the decadal evolution of tornado reports in the USA from 1920-1999 (Dotzek et al., 2005, their Fig. 3) substantiates this statement. The number of reported weak tornadoes in the USA started to rise from about 1953 on, when tornado research, forecasts and warnings were put on a professional basis there. Towards the end of the 1990s, the number of F0 tornadoes had increased dramatically compared to the pre-1950 era, whereas 

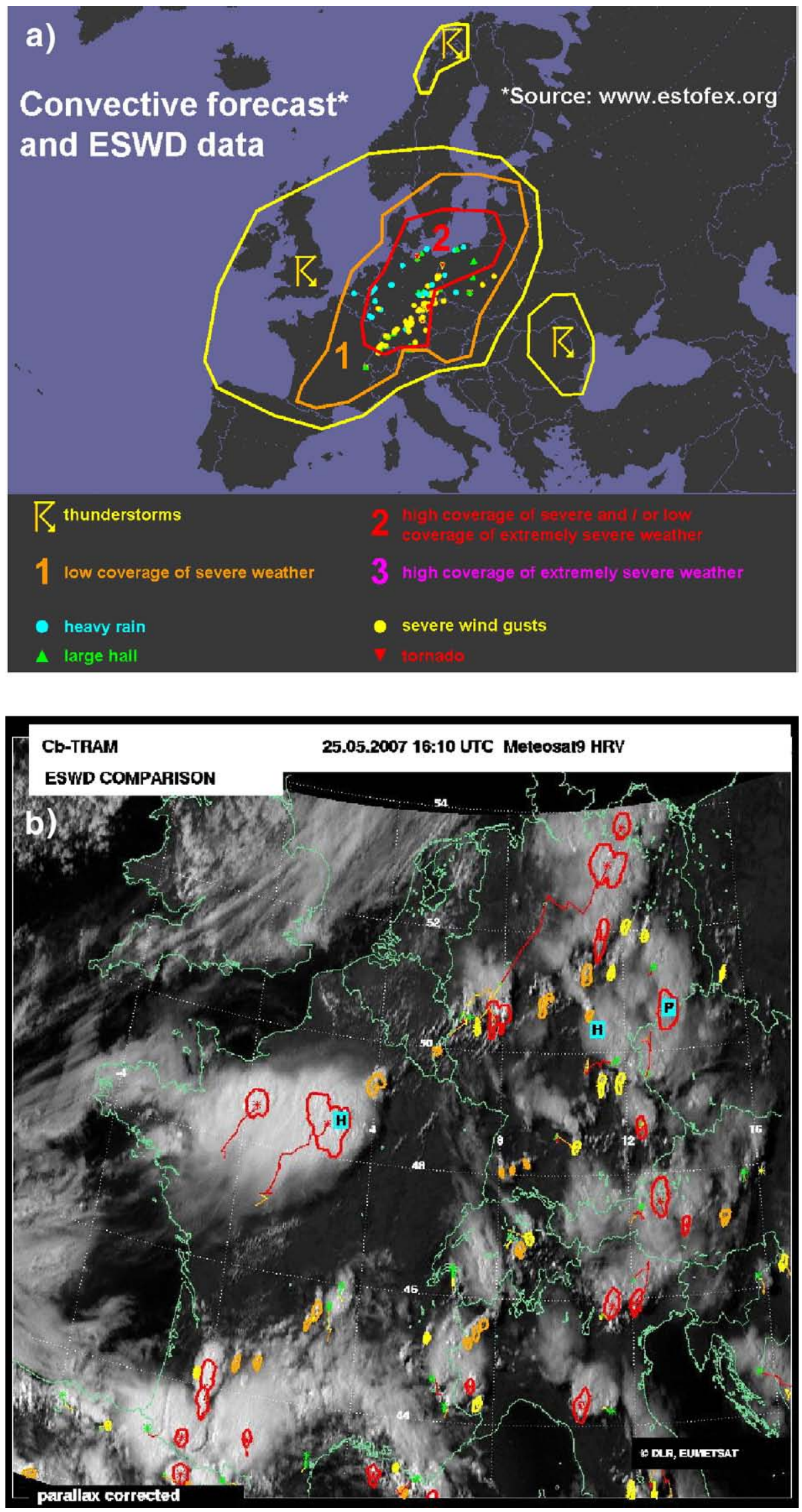


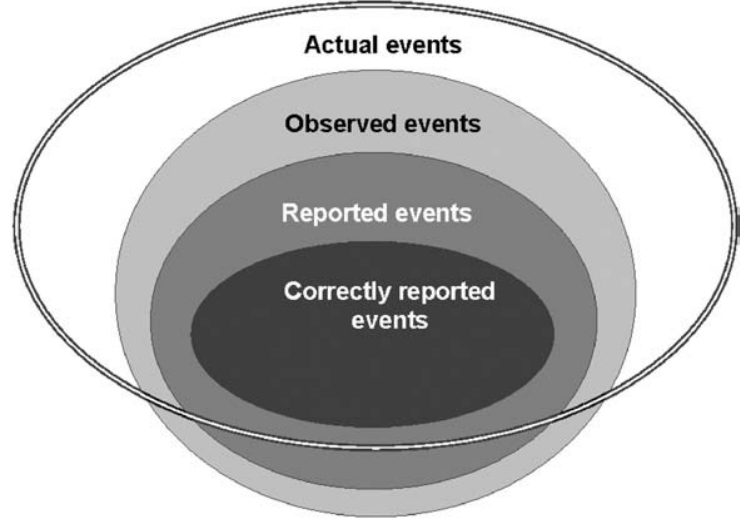

Fig. 5. Venn diagram illustrating the general reporting challenge in recording severe storm events, as well as the most likely explanation of the recent strong rise in severe storm reports in Europe. The parts of the set of observed and reported events lying outside the set of actual events denote observations falsely classified as severe storm phenomena, for instance, a mere $\mathrm{Cu}$ frac appendage triggering a funnel cloud report.

the number of significant tornado (F2 or stronger) reports remained approximately constant over the years, apart from some secular trends discussed in detail by Verbout et al. (2006), Brooks and Dotzek (2008), or Doswell et al. (2008). So if the increase in reported weak events in Europe nowadays were caused by climate change, then an identical climate change would have to have taken place in the USA fifty years earlier which is implausible.

Fig. 5 illustrates the potential magnitude of this reporting effect. The difference between the number of actual events and the number of correctly reported events is large whenever a climatology and reporting program for severe local storms is initiated. The main objective of the climatologist must be to bring the size of the set of correct reports as close as possible to the number of actual events. To reach a reporting efficiency of $100 \%$ is unrealistic and also not necessary. What is more important is consistency of the reporting system, that is, the reporting efficiency should converge to a stationary and homogeneous percentage. Such stable sampling would form the basis for any analysis aiming at separating reporting trends from physical trends, such as possibly due to climate change.

Other natural disaster databases face the same or similar challenges. Among these databases are Munich Re's worldwide NatCatSERVICE (www.munichre.com/en/ts/geo_risks/ natcatservice/default.aspx), "CRED” or EM-DAT (www.emdat. be), SHELDUS (www.sheldus.org) for the USA, "La Red" or DesInventar (www.desinventar.org/en/) for South America, or the WMO "severe world-weather" portal (severe.worldweather.wmo.int) which is based on SYNOP reports transmitted via the WMO Global Telecommunication System (GTS).

None of the databases above which provide European (i.e., WMO region VI) coverage is exactly comparable to the ESWD, but they all have different foci. Either the databases concentrate on very large events or those which cause substantial amounts of (insured) losses, or their scope of included severe thunderstorm phenomena is less detailed, or their data density is much less than in the ESWD, e.g. when relying on SYNOP reports alone. A general weakness of the databases initiated from the science community (like ESWD or SHELDUS) is that their data on losses are sparse or at least too low in many cases, as the final losses caused by extreme weather events often exceed the immediate post-event estimates in the media by far. Here, the insurance-related databases like NatCatSERVICE can quantify the loss amounts much better, but provide less information on meteorological details or merge many individual and local severe weather damage reports to a single entry in their data.

So while the databases above are all of a high quality in their specialised fields of application, a database focusing on local ground-truth severe convective storm reports with a high level of meteorological detail and with a pan-European scope was unavailable. The ESWD closes this gap and thus enables applications like those illustrated in this paper.

\section{Conclusions}

Two years have passed since founding the ESSL, and the following résumé of the main actions and research results can be given:

- The ESWD provides increasingly homogeneous pan-European coverage of severe thunderstorm reports in a detailed and flexible data format including metadata information;

- The NMHS: AEMet, DWD, NIMH and ZAMG are present cooperation partners. Additional collaboration with more European NMHS is highly welcome in order to enhance completeness and reusability of the database;

- With the new ESWD version 3, collaborating NMHS may opt to either run their local installations of the ESWD database software, to access the ESWD via protected user interfaces with edit permission for reports from their respective country, or start by contributing via the public interface;

- The partner NMHS perform quality-control for ESWD data gathered in their countries. For ESSL's own, and the public severe weather reports entered on the main ESWD site, the three-level QC is to be performed by ESSL;

- The ESWD data can successfully be applied in climatology and hazard assessments and allows for comparative studies with regions prone to severe weather outside Europe;

- The E-scale developed by ESSL as a wind speed scale is based on physical quantities and can be calibrated. Its development was triggered by ESSL's work on global tornado intensity distributions;

- A severe weather episode in Central Europe in July 2005 showed that ESWD reports can be applied to verify severe weather forecasts, watches or warnings as issued by NMHS;

- A satellite-based nowcasting verification study showed that ESWD reports were consistently correlated to Cb-TRAM objects. Up to $47 \%$ corresponded exactly (report in detection

Fig. 4. (a) The ESTOFEX network's threat-level Convective Forecast (polygons) for 29 July 2005 and ESWD reports (symbols as in Fig. 1). Aside from the general thunderstorm area, ESTOFEX threat levels 1 and 2 were active on this day. (b) Snapshot from the Cb-TRAM (Zinner et al., 2008) nowcasting (coloured polygons, yellow: onset of convection, orange: rapid vertical development, red: mature thunderstorm) for 25 May 2007,1610 UTC Meteosat-8 satellite image time. ESWD reports between 1600 and 1615 UTC are plotted as light blue squares with letters $\mathrm{H}=$ large hail and $\mathrm{P}=$ heavy precipitation. 
polygon), while substantially more reports lay close by these polygons.

The severe thunderstorm research community in Europe is evolving so rapidly that we can expect a significantly augmented ESWD database in a few years. This will enable analyses which are still far beyond of the scope of the present paper.

\section{Acknowledgements}

The authors would like to thank all ten founding members of the ESSL (aside from the authors: Dario Giaiotti and Fulvio Stel from Italy, Carmen Llasat and Romualdo Romero from Spain, Martin Setvák from the Czech Republic, and Jenni Teittinen from Finland) and numerous other colleagues from Europe and the USA for their support and encouragement over the last years. We thank Caroline Forster for the fruitful collaboration in the Cb-TRAM verification case study and highly appreciate the valuable suggestions to improve the paper from our two referees.

\section{References}

Bissolli, P., Grieser, J., Dotzek, N., Welsch, M., 2007. Tornadoes in Germany 1950-2003 and their relation to particular weather conditions. Glob. Planet. Change. 57, 124-138.

Brooks, H.E., 2004. On the relationship of tornado path length and width to intensity. Weather Forecast. 19, 310-319.

Brooks, H.E., Dotzek, N., 2008. The spatial distribution of severe convective storms and an analysis of their secular changes. In: Diaz, H.F., Murnane, R.J. (Eds.), Climate Extremes and Society, vol. 35-53. Cambridge University Press, Cambridge. 340 pp.

Court, A., 1970. Tornado Incidence Maps. ESSA Tech. Mem. ERLTM-NSSL, vol 49. $76 \mathrm{pp}$.

Doswell, C.A., Brooks, H.E., Maddox, R.A., 1996. Flash flood forecasting: an ingredients-based methodology. Weather Forecast. 11, 560-580.

Doswell, C.A., Brooks, H.E., Dotzek, N., 2009. On the implementation of the Enhanced Fujita scale in the USA. Atmos. Res. 93, 554-563 (this volume) doi:10.1016/j.atmosres.2008.11.003.

Dotzek, N., 2001. Tornadoes in Germany. Atmos. Res. 56, 233-251.

Dotzek, N., 2003. An updated estimate of tornado occurrence in Europe. Atmos. Res. 67-68, 153-161.

Dotzek, N., 2009. Derivation of physically motivated wind speed scales. Atmos. Res. 93, 564-574 (this volume). doi:10.1016/j.atmosres.2008.10.015.

Dotzek, N., Forster, C., 2009. Use of the European Severe Weather Database to verify of satellite-based storm detection or nowcasting. Proc. EUMETSAT Meteor. Sat. Conf., Darmstadt, Germany, 8-12 September 2008. 8 pp. [Available at www.eumetsat.int/Home/Main/Publications/Conference_and_Workshop_Proceedings/].

Dotzek, N., Friedrich, K., 2009. Downburst-producing thunderstorms in southern Germany: Radar analysis and predictability. Atmos. Res. 93, 457-473 (this volume).

Dotzek, N., Berz, G., Rauch, E., Peterson, R.E., 2000: Die Bedeutung von Johannes P. Letzmanns "Richtlinien zur Erforschung von Tromben, Tornados, Wasserhosen und Kleintromben" für die heutige Tornadoforschung. (The relevance of Johannes P. Letzmann's “Guidelines for research on tornadoes, waterspouts, and whirlwinds" for contemporary tornado research). Meteorol. Z. 9, 165-174. [In German, available under "Publications" at http://www.essl.org].

Dotzek, N., Grieser, J., Brooks, H.E., 2003. Statistical modeling of tornado intensity distributions. Atmos. Res. 67-68, 163-187.

Dotzek, N., Kurgansky, M.V., Grieser, J., Feuerstein, B., Névir, P., 2005. Observational evidence for exponential tornado intensity distributions over specific kinetic energy. Geophys. Res. Lett. 32, L24813. doi:10.1029/ 2005 GL024583.

Dotzek, N., Kratzsch, T., and Groenemeijer, P., 2006: The European Severe Weather Database (ESWD): An inventory of convective high-impact weather events for forecast and warning evaluation, climatology, and risk assessment. Preprints, 2nd THORPEX International Science Symposium (STISS), Landshut, 4-8 December 2006, WMO/TD No. 1355, WWRP/THORPEX No. 7, 228-229.

Dotzek, N., Lang, P., Hagen, M., Fehr, T., Hellmiss, W., 2007. Doppler radar observation, CG lightning activity, and aerial survey of a multiple downburst in southern Germany on 23 March 2001. Atmos. Res. 83, 519-533.

Dotzek, N., Emeis, S., Lefebvre, C., and Gerpott, J., 2008: Waterspouts over the North and Baltic Seas: Observations and climatology, predictability and reporting. Meteorol. Z. submitted.

Feuerstein, B., Dotzek, N., Grieser, J., 2005. Assessing a tornado climatology from global tornado intensity distributions. J. Climate. 18, 585-596.

Fujita, T.T., 1971. Proposed characterization of tornadoes and hurricanes by area and intensity. SMRP research paper no. 91, University of Chicago. 42 pp.

Fujita, T.T., 1981. Tornadoes and downbursts in the context of generalized planetary scales. J. Atmos. Sci. 38, 1511-1534.

Groenemeijer, P., Dotzek, N., Stel, F., Brooks, H., Doswell, C., Elsom, D., Giaiotti, D., Gilbert, A., Holzer, A., Meaden, T., Salek, M., Teittinen, J., and Behrendt, J., 2004: ESWD - A standardized, flexible data format for severe weather reports. Preprints, 3rd European Conf. on Severe Storms, León, 9.-12. November 2004, 2 pp. [Available at www.essl.org/projects/ESWD/].

Groenemeijer, P., Dotzek, N., Stel, F., Giaiotti, D., 2005. First results of the European Severe Weather Database ESWD. Preprints, 5th Ann. Meeting of the European Meteor. Soc., Utrecht, 12.-16. September 2005. [Available at www.essl.org/projects/ESWD/].

Hubrig, M., 2004. Analyse von Tornado- und Downburst-Windschäden an Bäumen (Analysis of tornado and downburst wind damage to trees). Forst Holz 59, 78-84 [In German].

IPCC, 2007. Climate Change 2007: The Physical Science Basis. Cambridge University Press, Cambridge. 996 pp.

Lalaurette, F., 2003. Early detection of abnormal weather conditions using a probabilistic extreme forecast index. Q. J. R. Meteorol. Soc. 129, 3037-3057.

Marshall, T.P., Robinson, S., 2006. Birmingham U.K. tornado: 28 July 2005. Preprints, 23rd Conf. on Severe Local Storms, St. Louis, 6.-10 November 2006. [Available at ams.confex.com/ams/23SLS/techprogram/ paper_115203.htm].

Meaden, G.T., 1976. Tornadoes in Britain: their intensities and distribution in space and time. J. Meteorol. 1, 242-251.

Névir, P., 2004. Ertel's vorticity theorems, the particle relabelling symmetry and the energy-vorticity theory of fluid mechanics. Meteorol. Z. 13, 485-498.

Thom, H.C.S., 1963. Tornado probabilities. Mon. Weather Rev. 91, 730-736.

Verbout, S.M., Brooks, H.E., Leslie, L.M., Schultz, D.M., 2006. Evolution of the U.S. tornado database: 1954-2003. Weather Forecast. 21, 86-93.

Wegener, A., 1917: Wind- und Wasserhosen in Europa (Tornadoes in Europe). Verlag Friedrich Vieweg und Sohn, Braunschweig, 301 pp. [In German, available under "References" at www.essl.org].

Zinner, T., Mannstein, H., Tafferner, A., 2008. Cb-TRAM: tracking and monitoring severe convection from onset over rapid development to mature phase using multi-channel Meteosat-8 SEVIRI data. Meteorol. Atmos. Phys. doi:10.1007/s00703-008-0290-y. 